\title{
Acil Serviste Pulmoner Emboli Tanısı Alan Hastalarda Laboratuar ve Görüntüleme Yöntemlerinin Tanısal Değeri
}

\section{Diagnostic Values of Laboratory and Imaging Methods for the Patients with Pulmonary Embolism in the Emergency Service}

\author{
${ }^{1}$ Fatma DURAN MEMIȘ, ${ }^{2}$ Murat YÜCEL, ${ }^{2}$ Yusuf YÜRÜMEZ, ${ }^{3}$ Bahri ELMAS, \\ ${ }^{4}$ Yasemin YILDIZ KIRAZALDI
}

\author{
${ }^{1}$ Bursa Uludağ Üniversitesi, Sağlık Bilimleri Fakültesi, Hemşirelik Bölümü, Bursa \\ ${ }^{1}$ Erzincan Mengücek Gazi Eğitim Ve Araștırma Hastanesi, Acil Tıp Kliniği, Erzincan \\ ${ }^{2}$ Sakarya Üniversitesi Tıp Fakültesi, Acil Tıp Anabilim Dalı, Sakarya \\ ${ }^{3}$ Sakarya Üniversitesi Tıp Fakültesi, Çocuk Sağlığı ve Hastalıkları Anabilim Dalı, Sakarya \\ ${ }^{4}$ Sakarya Üniversitesi Eğitim ve Araştırma Hastanesi, Acil Tıp Kliniği, Sakarya \\ Fatma Duran Memiș: https://orcid.org/0000-0001-7244-6958 \\ Murat Yücel: https://orcid.org/0000-0003-0220-9230 \\ Yusuf Yürümez: https://orcid.org/ 0000-0003-3917-9434 \\ Bahri Elmas: https://orcid.org/0000-0001-9034-6109 \\ Yasemin Yildız Kirazaldı: https://orcid.org/0000-0001-7244-6168
}

\begin{abstract}
ÖZ
Amaç: Pulmoner Emboli (PE) pulmoner arter veya dallarının trombüsle aniden tıkanması sonucu ortaya çıan mortalitesi yüksek bir hastalıktır. Bu çalışmada acil servise gelen PE olan hastalardaki tanı konulmadan santral ve periferik dal tutulumunu tespit etmedeki anamnez, laboratuar ve görüntüleme yöntemlerinin etkinliğinin analiz edilmesi amaçlanmıștır.

Materyal ve Metot: Çalışmamızda PE tanısı alan 103 hastanın anamnez,laboratuar ve görüntüleme yöntemleri santarl ve periferik dal tutulumu açısından karşılaştırıldı.

Bulgular: Santral ve periferik dal tutulumu karş1laştırıldığında hs-Troponin I ve laktat değerlerde anlamlı fark bulundu ( $\mathrm{p}$ değerleri sirasıyla: $\mathrm{p}=0,003 ; \mathrm{p}=0,003$ ) Santral dal tutulumu olan grubun optimal laktat kesme değeri ROC analizi ile 2,45 bulundu.

Sonuç: hs-Troponin ve laktat değerlerinin santral ve periferik dal tutulumu karşılaştırıldığında anlamlı farklı olduğu bulunmuştur ve bunun PE tanısinda santral ve periferik tutulum ayrımı için kullanılabileceği ön görülmüştür. Ancak bu sonucu destekleyecek ilave çalışmalara ihtiyaç vardır.
\end{abstract}

Anahtar Kelimeler: Acil, emboli, pulmoner

\section{ABSTRACT}

Objective: Pulmonary Embolism (PE) is a disease with high mortality caused by sudden blockage of the pulmonary artery or its branches with thrombus. In this study, it was aimed to analyze the effectiveness of anamnesis, laboratory and imaging methods in detecting central and peripheral branch involvement in patients with PE who came to the emergency department without making a diagnosis.

Materials and Methods: The study has been implemented 103 patients, who received the diagnose of $\mathrm{PE}$, in terms of anamnesis, laboratory and imaging methods after they have been dived into central and peripheral branch involvement.

Results: When central and peripheral branch involvement were compared, a significant difference was found in hsTroponin I and lactate values ( $p$ values, respectively: $p=$ $0.003 ; p=0.003$ ). The optimal lactate cut-off value of the group with central branch involvement was 2.45 by ROC analysis.

Conclusion: hs-Troponin and lactate values were found to be significantly different when compared to central and peripheral branch involvement, and it was proposed that this could be used for central and peripheral involvement in the diagnosis of PE. However, additional studies which will bolster this outcome are needed.

Keywords: Emergency, embolism, pulmonary

Yayın Bilgisi / Article Info:

Gönderi Tarihi/ Received: 20.06.2019

Sorumlu Yazar / Corresponding Author:

Fatma Duran Memis

$\begin{array}{ll}\text { Erzincan Mengücek Gazi Eğitim ve Araştırma Hastanesi, Acil Tıp Kabul Tarihi/ Accepted: 24.06.2019 } \\ \text { Kliniği, Erzincan } & \text { Online Yayın Tarihi/ Published: 30/06/2020 }\end{array}$

Telefon: 05359333618

E-mail: ftmdrn@hotmail.com 


\section{GÍRIŞ}

Pulmoner Emboli (PE), pulmoner arter veya dallar1nın trombüsle aniden tıkanması sonucu ortaya çıkan mortalitesi yüksek bir hastalıktır. ${ }^{1}$ Amerika Birleşik Devletleri'nde her yıl yaklaşık 200.000 kişiye yeni PE tanısı konulmaktadır. Klinik belirtilerin ve işaretlerin çeşitliliği nedeniyle teşhis koymak zordur. ${ }^{2}$

PE'de amaç trombüsün oluşumunun engellenmesi olmalıdır. PE şüphesinde hangi olguda ileri incelemenin gerektiğinin belirlenmesine yardımcı olacak sınıflamalara gereksinim duyulmuştur. ${ }^{3}$ En geçerli onaylanmış PE tahmin sistemi ise Welss skorudur. Skorlamaları takiben önerilen bir sonraki adımda ise D-dimer düzeyi yer alır. Ancak D-dimer düzeye hassas bir test olarak bilinse de spesifik değildir. ${ }^{4}$ Diğer taraftan prognostik değer taşıyan biyobelirteçler olarakta brain natriüretik peptik (BNP), N-terminal pro-brain natri üretik peptit (NTpro BNP), Troponin-I ve T ile kalp tipi yağ asit bağlayıcı protein ön plana çıkmaktadır. Ancak bunların hemodinami bakımından iyi durumda olan hastalarda pozitif prediktif değerlerinden çok negatif prediktif değerlerinin yüksek olduğu, bu nedenle erken taburcu edilme konusunda karar vermek için daha çok işe yarayacağı akılda tutulmalıdır. Diğer biyobelirteçlerin ise rutin kullanım için benimsenebilmesi için daha fazla klinik veriye ihtiyaç vardır. ${ }^{5}$ Klinik olarak şüphe duyulan hastalarda PE olma olasılığı yaklaşık olarak \% 35 civarındadır ve esas olarak tanısal yaklaşımda görüntüleme teknikleri ön plana çıkmaktadır. ${ }^{2,6}$ Bilgisayarlı Tomografi Pulmoner Anjiyografi (BTPA), PE'den kaynaklanan dolum kusurlarının ayrıntılı bir şekilde dağılımı ile pulmoner arterleri görüntüleme yeteneğine sahiptir. $^{7,8}$

$\mathrm{Bu}$ çalışmada acil servise gelen PE olan hastalarda tan konulmadan santral ve periferik dal tutulumunu tespit etmedeki anamnez, laboratuar ve görüntüleme yöntemlerinin etkinliğinin analiz edilmesi amaçlanmiştır.

\section{MATERYAL VE METOT}

Bu çalışma 1 Ocak 2015 ile 31 Aralık 2016 tarihleri arasındaki iki yıllık süreyi kapsayacak şekilde Sakarya Üniversitesi Eğitim ve Araştırma Hastanesi Acil Tıp Kliniğine başvuran ve PE tanısı ile yatışı yapilan hastalardan dahil edilme kriterlerine uyan 103 hastanın retrospektif olarak dosya kayıtlarının incelenmesi ile gerçekleştirildi. Araştırmanın verileri toplanmadan önce Sakarya Üniversitesi Klinik Araştırmalar Etik Kurulundan 19.04.2017 tarih ve '71522473/050.01.04.94' sayılı onay alındı. Araştır- manın yürütüleceği kurumdan yazılı izin alındı. Aynı zamanda araştırmanın kapsamı konusunda hastalara bilgi verilerek sözlü onam alındı.

PE hasta grubu acil servis kayitları ve bu hastalara ait hastane otomasyon sistemindeki elektronik kayıtlar gözden geçirilerek tespit edildi. BTPA sonucuna göre PE tanısı kesin olarak konulan tüm hastalar çalışmaya dâhil edildi. PE daha önemli hastalığı olan (şok ve miyokard enfarktüsü gibi), pıhtılaşma bozukluğu olan, PE tanısı konulan ancak yatış yapılmayıp ayaktan takip kararı verilenler ve BTPA çekilemeyen hastalar ise çalışma dışı bırakıldı.

PE olan hastalar BTPA'deki lokalizasyona göre; santral ve periferik dal tutulumu olmak üzere iki gruba ayrild.

Santral dal tutulumu: Ana pulmoner arter ve/veya sol ve/veya sağ ana pulmoner arterde trombüs olmaS1

Periferik dal tutulumu: Lob ve/veya segmental pulmoner arterde ve/veya subsegmental pulmoner arterde trombüs olması.

Çalışma kapsamında hastalara ait demografik veriler (yaş ve cinsiyet), başvuru şikâyetleri, özgeçmiş bilgileri, Wells Skoru ( $\leq 4$ ve $>4$ olacak şekilde), vital bulguları (sistolik ve diastolik tansiyon (TA), Nabı, ve $\mathrm{SpO} 2$ ), k1sa dönem mortalite, hematolojik ve biyokimyasal analiz sonuçları (Hemoglobin, RDW, Platelet/Lenfosit oranı (PLR), Nötrofil/Lenfosit oranı (NLR), INR, High Sensitive Troponin I (hsTroponin) ve High Sensitive CRP (hs-CRP) ve kan gazı değerlerine (PH, PO2, PCO2 ve Laktat) ait bulguları kaydedildi. Elde edilen tüm bu veriler santral ve periferik dal tutulumuna göre bir farkın olup olmaması açısından karşılaştırıldı.

Verilerin istatistiksel analizinde SPSS (Statistical Package for Social Sciences) 20.0 version Windows software (SPSS Windows; Chicago, IL, USA) programı kullanıldı. Verilerin dağılımlarını belirlemek için Kolmogorov-Simirnov testi kullanıldı. Buna göre sayısal verilerin dağılımı durumuna göre değişkenler ortalama $\pm \mathrm{SD}$, ortanca (minimummaksimum) olarak ve kategorik verilerde ise $n$ ve yüzde (\%) olarak verildi. İki değişkenli kategoride $\chi^{2}$ (ki-kare) testive sayısal verilerin kategorisinde ise Student $\mathrm{T}$ ve Mann Whitney U testleri kullanıldı. Verilerin santral ve periferik dal tutulumu tanısını koymada optimum cut off değerleri, sensitivite ve spesifite belirlenmesi için ROC (Receıver Operatıng Caracterıstıc) analizi yapıld1. $\mathrm{p}<0,05$ bulunanlar istatistiksel olarak anlamlı kabul edildi.

\section{BULGULAR}


Yaş açısından her iki grup karşılaştırıldı ğında santral dal tutulumu olan grubun periferik dal tutulumu olan gruptan daha yaşlı olduğu ancak bu durumun istatistiksel olarak anlamlı bir fark oluşturmadığı saptandı $(\mathrm{p}=0,311)$ (Tablo 1). Cinsiyet açısından karşılaştırıldığında hem santral dal tutulumu hem de periferik dal tutulumu olan hastalarda kadınların daha fazla olduğu gözlendi. Buna karşılık santral dal tutulumu ile periferik dal tutulumu cinsiyet açısından karşılaştırıldığında ise istatistiksel olarak anlamlı bir farkın oluşmadığ 1 saptandı $(p=0,614)$ (Tablo 1) .

Hem santral dal tutulumunda hem de periferik dal tutulumunda en sık şikâyetlerin nefes darlığı, göğüs ağrısı ve konfüzyon/nöbet olduğu, ancak bu durumun istatistiksel olarak anlamlı bir farkın oluşmadığ saptand $1(\mathrm{p}=0,9)$ (Tablo 1). Hastaların çoğunun özgeçmişinde özellik saptanmaz iken hem santral dal tutulumunda hem de periferik dal tutulumunda en sık operasyon ve PE öyküsü olduğu saptandı. Hipertansiyon öyküsünün ise yalnızca santral dal tutulumunda görüldüğü, periferik dal tutulumunda ise görülmediği tespit edildi. Ancak bu durumun istatistiksel olarak anlamlı bir fark oluşturmadığ $(\mathrm{p}=0,6)$ (Tablo 1).

Hastaların hesaplanmış Wells Skoru değerlendirildiğinde $>4$ olanların daha fazla bulunduğu ancak bu durumun her iki grup arasında istatistiksel olarak anlamlı bir fark oluşturmadığı saptandı $(p=0,421)$ (Tablo 2). Hastaların vital bulgularına bakıldığında santral dal tutulumu olan grupta nabız değerinin periferik gruba göre daha yüksek bulunmasına rağmen bu durumun istatistiksel olarak anlamlı bir farkın oluşmadığı saptandı $(\mathrm{p}=0,106)$ (Tablo 2). Vital bulgular açısından (sistolik ve diastolik TA, nabız ile $\mathrm{SpO}_{2}$ ) her iki grup arasında istatistiksel olarak anlamlı bir farkın oluşmadı̆̆ saptand $1 ~(\mathrm{p}=0,619$; $\mathrm{p}=0,694 ; \mathrm{p}=0,106 ; \mathrm{p}=0,39$ ) ( Tablo 2). Hastaların kısa dönem mortalitelerine bakıldığında ise santral dal tutulumu olan grupta daha fazla sayida mortalite olmasına rağmen her iki grup arasında istatistiksel olarak anlamlı bir farkın oluşmadığı saptand 1 $(\mathrm{p}=0,218)$ (Tablo 2).

Hastaların hematolojik analiz sonuçlarına bakıld1ğında santral ve periferik dal tutulumu karşılaştırıldığında her iki grup arasında istatistiksel olarak anlamlı fark bulunmadı ( $>0,05$ ) (Tablo 3). Hastaların biyokimyasal analiz sonuçlarına bakıldığında santral ve periferik dal tutulumu karşılaştırıldığında her iki grup arasında D-dimer, INR, hs-CRP değerleri arasında anlamlı fark saptanmadı ( $\mathrm{p}>0,05)$. Buna karşılik santral dal tutulumu olan grupla periferik dal tutulumu olan grup karşılaştırıldığında hs-Troponin I değerlerinin yüksek olduğu saptandı $(p=0,003)$ (Tablo 3). Santral ve periferik dal tutulumu karşılaştırıldığında her iki grup arasında $\mathrm{pH}, \mathrm{pCO}_{2}$ ve $\mathrm{pO}_{2}$ değerlerinde istatistiksel olarak anlamlı fark saptan$\operatorname{mad}_{1}(\mathrm{p}>0,05)$. Ancak santral ve periferik dal tutulumu karşılaştırıldığında laktat değerleri arasında istatistiksel olarak anlamlı fark tespit edildi $(\mathrm{p}=0,003)$ (Tablo 3).

Santral dal tutulumu olan grubun optimal laktat kesme değeri ise ROC analizi ile 2,45 olup sensitivitesi $\%$ 60, spesifitesi \% 75 saptandı (Șekil 1; Tablo 4).

\section{TARTISYMA VE SONUC}

PE mortaliteyi ve morbiditeyi azaltmak için hızlı tanınma, risk değerlendirmesi ve uygun tedavinin uygulanması gereken potansiyel ölümcül bir durumdur. ${ }^{9}$ PE'nin belirti ve bulgularının spesifik olmamas1 nedeniyle klinik tanısında güçlük yaşanabilmektedir. Tedavi edilemediği takdirde mortalite oranı \% 30'a kadar yükselirken, tedaviyle bu oran \% 3-10'a kadar düşmektedir. Mortalite oranının yüksek, tedaviye cevabın iyi olması nedeniyle PE'de erken tanı ve tedavi önemlidir. ${ }^{10}$

PE hastalarında yaş önemli bir risk faktörüdür. Yap1lan bazı çalışmalarda PE’nin orta ileri yaş populasyonda daha baskın olduğu gösterilmiştir. ${ }^{11,12}$ Stain ve ark. ${ }^{13}$ çalışmasında PE sıklığının yaşla orantılı olarak arttığı ve 50 yaşın üzerindeki kadınlarda daha sık görüldüğü saptanmıştır. Exter ve ark. ${ }^{14}$ çalışmasında yaş açısından subsegmental ve proksimal PE olan gruplar arasında anlamlı fark gözlemlenmemiştir. Benzer şekilde bizim çalışmamızda da santral ve periferik dal tutulumu karşılaştırıldığında yaş açısından anlamlı bir fark tespit edilmedi.

PE tanısı cinsiyet açısından değerlendirildiğinde erkeklerde daha fazla görüldüğü bilinmektedir. Literatüre bakıldığında bazı çalışmalarda kadın cinsiyetin daha fazla olduğu da gösterilmiştir ve bu durumun bölgesel farklılıklar nedeniyle olduğu düşünülmüştür. ${ }^{15}$ Jain ve ark. ${ }^{16}$ çalışmasında erkek cinsiyet fazla bulunmuş olup santral ve periferik dal karşılaştırılmasında anlamlı fark saptanmamıştır. Buna karşın Kubak ve ark. ${ }^{17}$ çalışmasında tutulan pulmoner dallar açısından cinsiyet değerlendirilmesinde kadın cinsiyetin fazla olduğu bulunmuş ancak bunun anlamlı bir fark oluşturmadığı saptanmıştır. Bizim çalışmamızda da kadın cinsiyet daha fazla görülmüş olmasına karşın santral ve periferik dal karşılaştırılmasında anlamlı bir fark saptanmamıştır. Biz de bu durumun bölgesel farklılıklardan kaynaklandığı kanisındayı. 
Acil serviste PE tanısı konulan hastalarda kardiyak troponin değerlerinin yüksek bulunduğuna dair çalışmalar vardır. ${ }^{18}$ PE'ye bağlı serum troponin değerlerindeki artışların akut miyokard enfarktüsünün aksine yaklaşık olarak 40 saat içinde normale dönmesi beklenir. ${ }^{19}$ Son zamanlarda, geleneksel tetkiklerle 'normal' aralıkta kabul edilen veya sifir olarak kaydedilecek olan troponin düzeylerini ölçmek için yeni nesil yüksek hassasiyetli troponin testleri geliştirilmiştir. Ancak yüksek duyarlıklı troponin T analizlerinin de PE'yi teşhis etmek için tek başına kullanılamayacağ1 gösterilmiştir. ${ }^{20}$ Buna karşın PE'de kardiyak troponin T'nin artmış olması erken mortalite ile ilişkili bulunmuştur. ${ }^{19,21,22} \mathrm{Bu}$ veriyi destekler nitelikte bir başka çalışmada da PE'de BTPA bulgularının kardiyak biyobelirteçler ile birlikte kullanıldığında akut PE'li hastaların mortalitesi ile anlamlı derecede ilişkili olduğu gözlemlenmiştir. ${ }^{23}$ Bizim çalışmamızda PE'dehs-Troponin I düzeylerinin santral dal tutulumunda periferik dal tutulumuna göre anlamlı yüksek olduğu saptanmıştır. Bu sonucumuz açısından bakıldığında bizim çalışmamıza benzer bir çalışma olmaması sebebiyle sonuçlarımızı özellikli kılmaktadır.

Akut faz reaktanlarından CRP'nin bazı çalışmalarda PE tanısında kullanılabileceği belirtilmiştir. ${ }^{24-26}$ Araz ve ark. $^{27}$ yaptı̆̆ 1 çalışmada masif ve submasif pulmoner emboli karşılaştırılmasında hs-CRP değerleri masif pulmoner embolide daha yüksek iken submasif pulmoner embolide daha düşük çıkmış ve her iki grup arasında anlamlı fark görülmüştür. Ateş ve ark. ${ }^{28}$ ile Crop ve ark. ${ }^{29}$ yaptığ çalışmada PE olan grup ile olmayan grup karşılaştırıldığında CRP değerleri PE olan grupta anlamlı yüksek bulunmuştur. Bizim çalışmamızda literatürü destekler nitelikte olup hs-CRP değerleri normal referans değerlerinden yüksek bulunmuştur. Ancak santral dal tutulumu ile periferik dal tutulumu karşılaştırıldığında ise anlamlı fark tespit edilmemiştir.

Arteriyel kan gazları, PE ciddiyeti hakkında da bir fikir verebilir. Bu konuda PIOPED çalışmasında ${ }^{30}$, PE'si olan ve olmayan hastalarda AKG anormallikleri karşılaştırılmış ve her iki grupta eşit bulgular saptanmıştır ve PE tanısının dışlanmasında $\mathrm{P}_{\mathrm{a}} \mathrm{O}_{2}$, $\mathrm{P}_{\mathrm{a}} \mathrm{CO}_{2}$ ve alveole-arteriyal oksijen gradient değerleri tek başına ve değişik kombinasyonlar şeklinde değerlendirilmiş ve önceden kardiyo pulmoner hastal1ğı olmayanların \% 30'unda, olanların ise \%14'ünde PE tanısı dışlanamamıştır. Bizim çalışma sonuçlarımizda bu sonucu destekler nitelikte olup santral dal tutulumu ile periferik dal tutulumu açısından $\mathrm{pH}$, $\mathrm{P}_{\mathrm{a}} \mathrm{O}_{2}$ ve $\mathrm{P}_{\mathrm{a}} \mathrm{CO}_{2}$ değerleri açısından anlamlı bir fark saptanmamıştır. Arteriyel kan gazı ile laktat konsantrasyonu acil serviste hızlıca test edilebilen bir diğer kan gazı parametresidir. Literatürde laktat yüksekliğinin hipoksi ile ilişkili olduğu ve sepsis gibi doku oksijenizasyonun azalmış olduğu hipoksik durumlarda anlamlı bir şekilde artacağından bahsedilmektedir. ${ }^{8}$ Bizim çalışmamızda da literatürü destekler nitelikte laktat değerleri yüksek bulunmuş ve laktat artıŞ1 santral dal tutulumu ile periferik dal tutulumuna göre daha fazla olduğu bu durumun anlamlı bir fark oluşturduğu gözlenmiştir. Bu konuda literatürde çalışma olmaması sonucumuzu özellikli kılmaktadır. Bulgularımıza göre hs-Troponin ve laktat değerlerinin santral ve periferik dal tutulumu karşılaştırıld1ğında santral dal tutulumu açısından anlamlı yüksek olduğu bulunmuştur ve bunun PE tanısında santral ve periferik tutulum ayrımı için kullanılabileceği ön görülmüştür. Ancak bu sonucu destekleyecek ilave çalışmalara ihtiyaç vardır.

Çalışmamızdaki hasta sayısı kısıtlılığı ve ek hastalıklar göz önüne alındığında bu konuyla ilgili daha fazla çalışma yapılmasına ihtiyaç vardır.

Etik Komite Onayı: Çalışma için Sakarya Üniversitesi Klinik Araştırmalar Etik Kurulu'ndan etik onayı alınd1. (Tarih: 19.04.2017 karar no: 71522473/050.01.04.94).

Çıkar Çatışması: Yazarlar çıkar çatışması bildirmemişlerdir.

Yazar Katkılart: Fikir - YY. MY ; Denetleme YY. MY; Malzemeler - FDM,YYK; Veri toplanmaS1 ve/veya işlemesi - FDM; Analiz ve/veya yorum BE ; Yazıyı yazan - FDM.

Hakem değerlendirmesi: D1ş bağımsız.

\section{KAYNAKLAR}

1. Gong JN, Yang YH. Current clinical management status of pulmonary embolism in china. Chin Med J (Engl). 2017;20;130(4):379381. doi: 10.4103/0366-6999.199841

2. Gülşen Z, Koşar PN, Gökharman FD. Comparison of multidetector computed tomography findings with clinical and laboratory data pulmonary thrombo embolism. Pol J Radiol. 2015;80:252-258. doi: 10.12659/ PJR.893793

3. Well PS, Anderson DR, Rodger $M$, et al. Derivation of a simpleclinical model to categorize patients probability of pulmonary embolism incrising the models utility with the Simpli RED D-dimer. Thromb Haemost. 2000;83 (3):416-20. 
4. Crane S, Jaconelli T, Eragat M. Retrospective validation of the pulmonary embolism rule-out criteria rule in 'PE unlikely' patients with suspected pulmonary embolism. European Journal of Emergency Medicine. 2016;09699546. doi: 10.1097/MEJ.0000000000000442

5. Konstantinides SV, Torbicki A, Agnelli G, et al. Spyropoulos, 2014 ESC Guidelines on the diagnosis and management of acute pulmonary embolism: The Task Force for the Diagnosis and Management of Acute Pulmonary Embolism of the European Society of Cardiology (ESC). European Heart Journal. 2014;35(43):30333080. doi: https://doi.org/10.1093/eurheartj/ ehu283

6. Remy JM, Deschildre F, Artaud D, et al. Diagnosis of pulmonary embolism with spiral CT comparison with pulmonary arteriography and scintigraphy. Radiology. 1996;200(3):699706.

7. Alhassan S, Sayf AA, Arsene C, Kreyem H. Suboptimal implementaion of diagnostic algorithms and over use of computed tomography pulmonary angiography in patients with suspected pulmonary embolism. Annals of Toracic Medicine. 2016;11:254-60. doi: 10.4103/1817-1737.191875

8. Türk Toraks Derneği Pulmoner Tromboembolizm Tanı Ve Tedavi Uzlaşı Raporu - 2015. www.toraks.org.tr/book.aspx? list $=1875 \&$ menu $=269 \&$ menu $=269$. Accessed March 3, 2019.

9. Apfaltrer P, Walter T, Gruettner $\mathrm{J}$, et al. Prediction of adverse clinical outcome in patients with acute pulmonary embolism: evaluation of high-sensitivity troponin I andquantitative CT parameters. European Journal of Radiology. 2013;82 (3):563-7. doi: 10.1016/j.ejrad.2012.11.009

10. Carson JL, Kelley MA, Duff A. The clinical course of pulmonary embolism. N EnglMed. 1992;326:1240-1245.

11. Janke RM, Mcgovern PG, Folsom Ar. Mortality, hospital discharges, and case fatality for pulmonary embolism in the Twin Cities 1980-1995. J Clin Epidemiol. 2000;53(1):103-9.

12. Siddique RM, Siddique MI, Rimm AA. Trends in pulmonary embolism in the US elderly population 1984- through 1991. Am J Public Health. 1998;88(3):478-480.
13. Stein PD, Hsiu Ling H, Afzal A. İncidence of acute pulmonary embolism in a general hospital. Chest. 1999;210:689-91.

14. Exter PL, Es JV, Klok AF. et al. Risk profile and clinical outcome of symptomatic subsegmental acute pulmonary embolism. Blood. 2013;122(7):1144-1149. doi: 10.1182/ blood-2013-04-497545

15. Lau JK, Chow V, Brown A, Kritharides L, Ng ACC. Predicting in-hospital death during acute presantation with pulmonary embolism to facilitate early discharge and outpatient manegement. Plos One. 2017;12(7):e0179755. doi: 10.1371/journal.pone.0179755

16. Jain CC, Chang Y, Kabrhel C, et al. Impact of pulmonary arterial clot location on pulmonary embolism treatment and outcomes (90 days). The American Journal of Cardiology. 2016;119 (5):802-807. doi: 10.1016/j.amjcard. 2016. 11. 018

17. Kubak MP, Lauritzen PM, Arne Borthne A, et al.elevated d-dimer cut-off values for computed tomography pulmonary angiography d-dimer correlates with location of embolism. Ann Transl Med. 2016;4(11):212. doi: 10.21037/ atm.2016.05.55

18. Özsu S, Bektas H, Abul Y, Ozlu T, Örem A. Value of cardiac troponin and sPESI in treatment of pulmonary thromboembolism at outpatient setting. Lung. 2015;193(4):559-65. doi: 10.1007/s00408-015-9727-5

19. Pruszczyk P, Kostrubiec M, Bochowicz A, et al. $\mathrm{N}$-terminal pro-brain natriuretic peptide in patients with pulmonary embolism. Eur Respir J. 2003;22(4):649-53.

20. Walter T, Apfaltrer P, Weilbacher F, et al. Predictive value og high-sensitivity troponin I and D-dimer assays for adverse outcome in patients with acute pulmonary embolism. Exp Ther Med. 2013;5(2):586-590. doi: 10.3892/ etm. 2012.825

21. Becattini C, Vedovati MC, Agnelli G. Prognostic value of troponins in acute pulmonary embolism: a meta-analysis. Circulation. 2007;116(4):427-33. doi: 10.1161/ CIRCULATIONAHA.106.680421

22. Giannitsis E, Müller-Bardorff M, Kurowski V, et al. Independent prognostic value of cardiac troponin $\mathrm{T}$ in patients with comfirmed pulmonary embolism. Circulation. 2000;102 (2):211-7. 
23. In E, Aydın AM, Özdemir C, Sökücü SN, Dağlı $\mathrm{MN}$. The efficacy of CT for detection of right ventricular dysfunction in acute pulmonary embolism, and comparison with cardiac biyomarkers. Japanese Journal of Radiology. 2015;33(8):471-478. doi: 10.1007/s11604-0150447-9

24. Maskel NA, Butland RJ.A normal serum CRP measurement does not exclude deep vein thrombosis. Thromb Haemost. 2001;86(6):15823.

25. Bucek RA, Reiter M, Quehenberger P, Minar E. $\mathrm{C}$-reactive protein in the diagnosis of deep vein thrombosis. Br J Haematol. 2002;119(2):385-9.

26. Aujesky D, Hayoz D, Yersin B, et al. Exclusion of pulmonaryembolismusing $\mathrm{C}$-reactive protein and D-dimer. A prospective comparison. Thromb Haemost. 2003;90(6):1198-203. doi: 10.1160/TH03-03-0175

27. Araz Ö, Yılmazel Uçar E, Yalcin A, et al. Predictive value of serum Hs-CRP levels for outcomes of pulmonary embolism. ClinRespir J. 2016;10(2):163-7. doi: 10.1111/crj.12196

28. Ateş H, Ateş I, Bozkurt B, et al. What is the most reliable marker in the differantial diagnosis of pulmonary embolism and communityacquired pneumonia? Blood Coagulation \& Fibrinolysis. 2016;27(3):252-258. doi: 10.1097/ MBC.0000000000000391

29. Crop MJ, Siemes C, Berendes P, et al. Influence of C-reactive protein levels anda ge on the value of D-dimer in diagnosing pulmonary embolism. Eur J Haematol. 2014;92(2):147-55. doi: 10.1111/ejh. 12218

30. PIOPED investigators. PİOPED-II Multidetector computed tomography for acute pulmonary embolism. N Engl J Med. 2006. doi: 10.1056/ NEJMoa052367 
Tablo 1. Santral ve periferik dal tutulumunda hastaların demografik veriler (yaş ve cinsiyet), başvuru şikâyetleri ve özgeçmiş bilgileri.

\begin{tabular}{|c|c|c|c|c|c|}
\hline \multicolumn{3}{|l|}{ Değişken } & \multirow{3}{*}{$\begin{array}{c}\text { Santral dal } \\
\mathbf{6 8 , 7} \pm \mathbf{1 5 , 5} \\
24 \\
\end{array}$} & Periferik dal & \multirow{2}{*}{$\begin{array}{l}P \\
0,311\end{array}$} \\
\hline \multirow{3}{*}{ Demografik veriler } & \multicolumn{2}{|c|}{ Yaş (ortanca, min-max) } & & $65 \pm 17,2$ & \\
\hline & \multirow{2}{*}{ Cinsiyet } & Erkek & & 13 & \multirow{2}{*}{0,614} \\
\hline & & Kadın & 46 & 20 & \\
\hline \multirow{7}{*}{ Başvuru Şikâyetleri } & \multicolumn{2}{|c|}{ Nefes darlığ 1} & 42 & 19 & \multirow{7}{*}{0,9} \\
\hline & \multicolumn{2}{|c|}{ Göğüs Ağrıs1 } & 12 & 5 & \\
\hline & \multicolumn{2}{|c|}{ Pre/Senkop } & 4 & 3 & \\
\hline & \multicolumn{2}{|c|}{ Konfüzyon/Nöbet } & 8 & 5 & \\
\hline & \multicolumn{2}{|c|}{ Öksürük } & 2 & 1 & \\
\hline & \multicolumn{2}{|c|}{ Hemoptizi } & 1 & 0 & \\
\hline & \multicolumn{2}{|l|}{ Diğer } & 1 & 0 & \\
\hline \multirow{10}{*}{ Özgeçmiş Bilgileri } & \multicolumn{2}{|c|}{ Pulmoner Emboli } & 7 & 3 & \multirow{10}{*}{0,6} \\
\hline & \multicolumn{2}{|c|}{ Operasyon } & 10 & 3 & \\
\hline & \multicolumn{2}{|c|}{ Aktik Kanser } & 4 & 2 & \\
\hline & \multicolumn{2}{|c|}{ Diyabetes Mellitus } & 5 & 1 & \\
\hline & \multicolumn{2}{|c|}{ Hipertansiyon } & 4 & 0 & \\
\hline & \multicolumn{2}{|c|}{ Koroner Arter Hastalığ1 } & 4 & 1 & \\
\hline & \multicolumn{2}{|c|}{ Serebrovasküler Hastalık } & 3 & 3 & \\
\hline & \multicolumn{2}{|c|}{ Kronik Böbrek Yetmezliği } & 0 & 1 & \\
\hline & \multicolumn{2}{|c|}{ Özellik yok } & 30 & 17 & \\
\hline & \multicolumn{2}{|l|}{ Diğger } & 4 & 1 & \\
\hline
\end{tabular}


Tablo 2. Santral ve periferik dal tutulumunda hastaların hesaplanmış Wells Skoru, vital bulguları ve k1sa dönem mortaliteleri.

\begin{tabular}{|c|c|c|c|c|}
\hline \multicolumn{2}{|l|}{ Değişken } & \multirow{2}{*}{$\begin{array}{l}\text { Santral dal } \\
26\end{array}$} & \multirow{2}{*}{$\begin{array}{l}\text { Periferik dal } \\
15\end{array}$} & \multirow{3}{*}{\begin{tabular}{|l|}
$\boldsymbol{P}$ \\
0,421
\end{tabular}} \\
\hline \multirow[t]{2}{*}{ Wells Skoru } & $\leq 4$ & & & \\
\hline & $>4$ & 44 & 18 & \\
\hline \multirow[t]{4}{*}{ Vital bulgular } & Sistolik TA (mm Hg) & $120 \pm 25,6$ & $123,4 \pm 22$ & 0,619 \\
\hline & Diastolik TA (mm Hg) & $73,5 \pm 14,5$ & $75,2 \pm 14,4$ & 0,694 \\
\hline & Nabız (dk) & $102,4 \pm 19,3$ & $95 \pm 21,7$ & 0,106 \\
\hline & $\mathrm{SpO}_{2}(\%)$ & $90,1 \pm 7,3$ & $91,5 \pm 7,1$ & 0,39 \\
\hline \multirow[t]{2}{*}{ Kısa dönem mortalite } & Var & 7 & 1 & \multirow{2}{*}{0,218} \\
\hline & Yok & 63 & 32 & \\
\hline
\end{tabular}

TA: tansiyon arteriyel; $\mathrm{SpO}_{2}$ : pulse oksimetre ile ölçülen saturasyon. 
Tablo 3. Santral ve periferik dal tutulumunda hastaların hematolojik, biyokimyasal ve kan gazı analiz sonuçları.

\begin{tabular}{|c|c|c|c|c|}
\hline \multicolumn{2}{|l|}{ Laboratuar } & Santral dal & Periferik dal & $P$ \\
\hline \multirow{4}{*}{$\begin{array}{l}\text { Hematolojik } \\
\text { analiz sonuçları }\end{array}$} & Hemoglobin (g/dl) & $12,5 \pm 1,5$ & $11,89 \pm 1,5$ & 0,83 \\
\hline & RDW (\%) & $17,1 \pm 2,66$ & $16,58 \pm 2,14$ & 0,2 \\
\hline & PLR (\%) & $125,3(11,6-778,5)$ & $123,1(4,7-483,3)$ & 0,808 \\
\hline & NLR (\%) & $3,7(0,6-37,7)$ & $3,7(1,4-147,3)$ & 0,708 \\
\hline \multirow{4}{*}{$\begin{array}{l}\text { Biyokimyasal } \\
\text { analiz sonuçları }\end{array}$} & D-DİMER (ng/ml) & $2611,5(73,7-30254,9)$ & $2465,4(186-7918,4)$ & 0,211 \\
\hline & INR & $1,1(0,9-3,4)$ & $1,08(0,9-1,5)$ & 0,8 \\
\hline & Hs-troponin (ng/ml) & $44,5(1,3-1253,9)$ & $12,55(0,3-5274,1)$ & 0,003 \\
\hline & CRP (mg/L) & $46,9(3-190)$ & $62,2(3-193)$ & 0,131 \\
\hline \multirow{4}{*}{$\begin{array}{l}\text { Kan gazı analiz } \\
\text { sonuçları }\end{array}$} & Laktat(mmol/L) & $2,6(1-10)$ & $1,8(0,8-4,8)$ & 0,003 \\
\hline & pH & $7,39 \pm 0,09$ & $7,41 \pm 0,074$ & 0,433 \\
\hline & $\mathrm{PCO}_{2}(\mathrm{mmHg})$ & $37,9(14,6-83)$ & $41,25(25,8-117)$ & 0,272 \\
\hline & $\mathrm{PO}_{2}(\mathrm{mmHg})$ & $34,85(15,7-104)$ & $48,6(20,6-87,9)$ & 0,189 \\
\hline
\end{tabular}

RDW: eritrosit dağllım genişliği; PLR: platelet/lenfosit oranı; NLR: nötrofil/lenfosit oranı; INR: uluslararası normalleştirilmiş oran; Hs-CRP: high sensitive c-reaktif protein; $p H$ : hidrojen gücü; PCO2: karbondioksit basincl; PO2: oksijen basincl. 


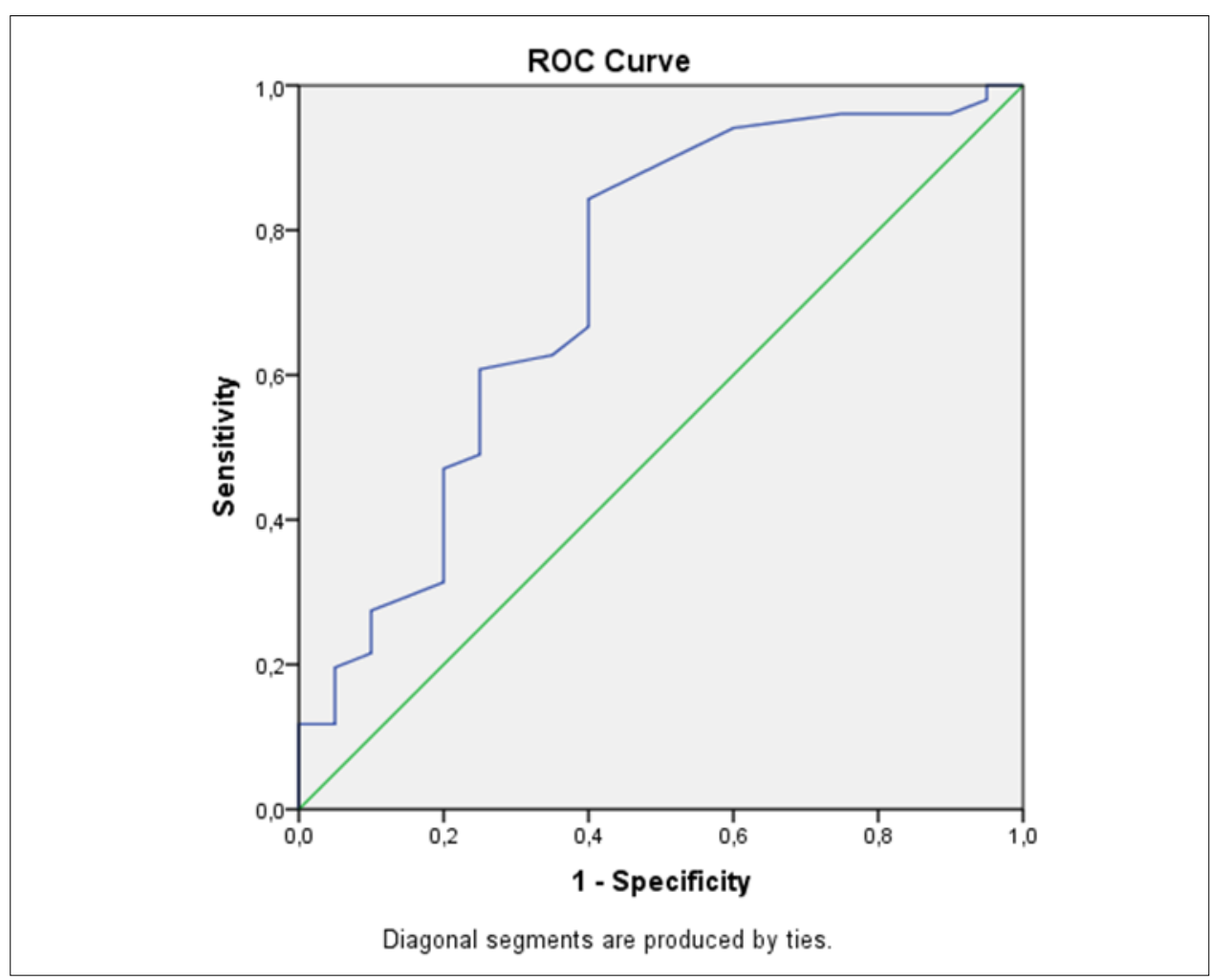

Şekil 1: Optimal laktat kesme değeri ROC analizi $(\mathrm{p}=0,004)$. 
Tablo 4. Optimal laktat kesme değeri ROC analizi.

\begin{tabular}{|c|c|c|c|c|c|c|c|c|}
\hline \multirow[b]{2}{*}{ Değişken } & \multirow[b]{2}{*}{ AUC } & \multirow[b]{2}{*}{$\begin{array}{l}\text { Standart } \\
\text { sapma }\end{array}$} & \multirow[b]{2}{*}{$\mathbf{p}$} & \multicolumn{2}{|c|}{$\begin{array}{l}\text { Asemptomatik 95\% Gü- } \\
\text { ven Aralığı }\end{array}$} & \multirow{2}{*}{$\begin{array}{l}\text { Optimum } \\
\text { Kesme } \\
\text { Değeri }\end{array}$} & \multirow[b]{2}{*}{ Sensitivite } & \multirow[b]{2}{*}{ Spesifisite } \\
\hline & & & & $\begin{array}{l}\text { Lower } \\
\text { Bound }\end{array}$ & $\begin{array}{l}\text { Upper } \\
\text { Bound }\end{array}$ & & & \\
\hline Laktat & 0,722 & 0,073 & 0,004 & 0,579 & 0,865 & 2,4500 & $\mathbf{0 , 6 0 0}$ & $\mathbf{0 , 7 5 0}$ \\
\hline
\end{tabular}

AUC: eğri altındaki alan. 